\title{
Evaluation of osteoarthritic changes in the temporomandibular joint and their correlations with age: A retrospective CBCT study
}

\section{Ocena zmian kostno-stawowych w stawie skroniowo-żuchwowym i ich związków z wiekiem - retrospektywne badanie CBCT}

\author{
Nagihan $\mathrm{Koç}^{\mathrm{A}-\mathrm{F}}$ \\ Department of Dentomaxillofacial Radiology, Faculty of Dentistry, Hacettepe University, Ankara, Turkey \\ A - research concept and design; B - collection and/or assembly of data; $C$ - data analysis and interpretation; \\ $D$ - writing the article; $E$ - critical revision of the article; $F$ - final approval of the article
}

Address for correspondence

Nagihan Koç

E-mail: nagihan.koc@hacettepe.edu.tr

\section{Funding sources}

None declared

Conflict of interest

None declared

\section{Acknowledgements}

The author would like to thank Zuhal Özateş for her assistance in the collection of the data.

This work was accepted for oral presentation with abstract publication at the $32^{\text {nd }}$ Annual Meeting of the European Society of Head and Neck Radiology, October 3-5, 2019, Cinisi, Palermo, Italy.

Received on July 29, 2019

Reviewed on August 31,2019

Accepted on September 16, 2019

Published online on January 30,2020

Cite as

Koç, N. Evaluation of osteoarthritic changes in the temporomandibular joint and their correlations with age: A retrospective CBCT study. Dent Med Probl. 2020;57(1):67-72. doi:10.17219/dmp/112392

DOI

$10.17219 / \mathrm{dmp} / 112392$

Copyright

๑ 2020 by Wroclaw Medical University

This is an article distributed under the terms of the

Creative Commons Attribution 3.0 Unported License (CC BY 3.0)

(https://creativecommons.org/licenses/by/3.0/)

\begin{abstract}
Background. Cone-beam computed tomography (CBCT) enables the radiographic examination and evaluation of osseous changes in the temporomandibular joint (TMJ).

Objectives. The aim of this study was to determine the prevalence of various bony changes in TMJ in patients from a wide age range as well as to evaluate the $\mathrm{CBCT}$ findings of TMJ osteoarthritis $(\mathrm{OA})$ and correlate them with age.
\end{abstract}

Material and methods. The study included the CBCT images of 150 patients (43 males and $107 \mathrm{fe}-$ males) who were refferred to the Department of Dentomaxillofacial Radiology for the evaluation of TMJs. Each TMJ was evaluated separately for the presence of any osseous changes in the condylar head or articular fossa/eminence, and for joint space narrowing.

Results. The mean age of the sample was 37.26 years (range: 10-90 years). A total of 101 (67.3\%) patients presented 1 or more osseous changes. No significant differences were found between the right and left TMJs concerning the prevalence rates of osseous changes. Significant differences were found in the mean ages with regard to the absence and presence of the following findings: condylar erosion, osteophytes, loose bodies, erosion in the articular fossa, and joint space narrowing.

Conclusions. Degenerative changes in TMJ may reflect an age-related bone remodeling process. Older patients may have more common findings of $\mathrm{OA}$, such as condylar and articular erosion, osteophytes, loose joint bodies, and joint space narrowing.

Key words: osteoarthritis, cone-beam computed tomography, temporomandibular joint

Słowa kluczowe: choroba zwyrodnieniowa stawów, komputerowa tomografia stożkowa, staw skroniowo-zuchwowy 


\section{Introduction}

Osteoarthritis $(\mathrm{OA})$ is a term that describes an age-related non-inflammatory disease starting with changes within the bone and spreading over the tissues of the joint to the subsequent degeneration of articular surfaces. ${ }^{1}$ This condition is sometimes called degenerative joint disease and involves a remodeling process that aims to adapt the structure of the temporomandibular joint (TMJ) to mechanical forces to ensure normal functioning. ${ }^{2}$ Excessive or continuing forces lead to the progressive degeneration of the bony articular surfaces of TMJ, which eventually results in the radiographic findings of $\mathrm{OA}$, such as flattening, the formation of osteophytes and loose bodies, erosion, a reduced joint space, subcortical sclerosis, and cysts. ${ }^{3}$ It should be noted that the remodeling of TMJ may be detected in the absence of symptoms and clinical signs. Severe osseous changes and the presence of clinical symptoms, such as pain or dysfunction, indicate the advanced stages of TMJ OA. ${ }^{4}$

Cone-beam computed tomography (CBCT) provides detailed 3-dimensional (3D) images for the diagnosis of degenerative changes in TMJ, at the same time ensuring a lower radiation dose, a shorter exposure time, a higher spatial resolution, and a lower cost as compared to computed tomography $(\mathrm{CT}){ }^{5,6}$ Although it is well-acknowledged that CBCT provides information about the osseous components of TMJ, it also images in detail the structures of TMJ, thereby contributing to the early detection and staging of OA as well as to the monitoring of changes in the disease over time. ${ }^{7}$ The Research Diagnostic Criteria for Temporomandibular Disorders (RDC/TMD) - a standardized protocol to diagnose TMD - was proposed in 1992 and has been developed to provide the image analysis for OA. ${ }^{2,8}$

The aim of this study was to determine the prevalence of various bony changes in TMJ in patients from a wide range of age as well as to evaluate the $\mathrm{CBCT}$ findings of TMJ OA and correlate them with age.

\section{Material and methods}

This retrospective study was approved by the Research Ethics Board of Hacettepe University in Ankara, Turkey (GO 19/02). The CBCT images of 150 patients (43 males and 107 females) referred to the Department of Dentomaxillofacial Radiology, Faculty of Dentistry of Hacettepe University for the evaluation of TMJs between June 2017 and May 2018 were included in the study.
The CBCT images were obtained using the $\mathrm{i}-\mathrm{CAT}^{\mathrm{TM}}$ Next Generation device (Imaging Sciences International, Hatfield, USA) with a tube voltage of $120 \mathrm{kV}$, a tube current of $5 \mathrm{~mA}$ and a voxel size of $0.2 \mathrm{~mm}$. All examinations were performed in a maximum intercuspation position. A series of axial views of 1-millimeter thickness was automatically produced following the reconstruction of the raw data. The TMJs were evaluated on the TMJ screen of the CBCT software from the lateral images perpendicular to the long axis of the condyle and coronal images parallel to the long axis of the condyle. ${ }^{9}$ The slice thickness and the distance between slices were $1 \mathrm{~mm}$. The presence of an osseous change was confirmed when it was detected in at least 2 consecutive slices. ${ }^{10}$

The mean age of the sample was 37.26 years (range: 10-90 years). Table 1 shows the distribution of the sample according to age and gender. A total number of 300 TMJs were evaluated. Age, gender and osseous changes were recorded for each patient. After excluding CBCT scans obtained for the imaging of initial injuries or the posttreatment evaluation of TMJ and inflammatory arthritis, the presence or absence of the following characteristics were evaluated based on $\mathrm{RDC} / \mathrm{TMD}^{2}$ :

- bony changes in the condylar head:

- flattening - the loss of the convex form of the articular surface,

- erosion - the loss of continuity in the cortical bone margin,

- osteophytes - marginal hypertrophy with sclerotic borders and the exophytic angular formation of the osseous tissue arising from the surface,

- loose joint bodies - calcified structures that are not continuous with the disk or osseous structures of the joint,

- subcortical sclerosis - an increase in the thickness of the cortical plate,

- a subchondral cyst - a cavity below the articular surface that deviates from the normal marrow pattern,

- condylar hypoplasia or hyperplasia - the size of the condyle is small or large from all dimensions, but its morphology is normal, and

- condylar bifidity ${ }^{2,11}$;

- bony changes in the articular fossa:

- erosion,

- sclerosis,

- resorption, and

- the flattening of the articular eminence ${ }^{9,11}$;

- joint space narrowing - a reduction in space $(<1.5 \mathrm{~mm})$ in all directions (anterior, superior and posterior). ${ }^{10}$

Table 1. Distribution of the sample according to age and gender

\begin{tabular}{|c|c|c|c|c|c|c|c|c|}
\hline \multirow{2}{*}{ Gender } & \multicolumn{6}{|c|}{ Age [years] } & \multirow{2}{*}{$\begin{array}{l}\text { Total } \\
\text { (n) }\end{array}$} & \multirow{2}{*}{$\begin{array}{c}\text { Percentage } \\
{[\%]}\end{array}$} \\
\hline & $10-19$ & $20-29$ & $30-39$ & $40-49$ & $50-59$ & $60+$ & & \\
\hline Male (n) & 8 & 11 & 6 & 3 & 9 & 6 & 43 & 28.7 \\
\hline Female (n) & 19 & 27 & 19 & 17 & 16 & 9 & 107 & 71.3 \\
\hline Total (n) & 27 & 38 & 25 & 20 & 25 & 15 & 150 & 100.0 \\
\hline
\end{tabular}




\section{Data analysis}

The IBM SPSS Statistics for Windows software, v. 23.0 (IBM Corp., Armonk, USA) was used for the data analysis and statistical procedures. The descriptive statistical data was recorded, and the independent samples $t$-test was conducted to assess the relationship between age and the percentages of degenerative bony changes. The prevalence rates of bony changes in the right and left sides were compared by means of McNemar's test. A $p$-value $<0.05$ was considered statistically significant.

\section{Results}

Out of the 150 patients included in this study, 49 patients $(32.7 \%)$ had no radiographic changes in the condyle, articular fossa/eminence or joint space, whereas 101 patients $(67.3 \%)$ did. The examplary images of osseous changes in the TMJs are shown in Fig. 1.

Table 2 shows the comparison of osseous changes with regard to the right and left TMJs. The results of McNemar's test showed that the prevalence rates among the 2 sides were not significantly different $(p=0.442)$.

Table 3 shows the frequency distribution of osseous changes according to patients and TMJs. Of the 300 TMJs, 108 (36\%) showed condylar flattening, 39 (13\%) showed condylar erosion, 30 (10\%) showed condylar osteophytes, $28(9.3 \%)$ showed condylar sclerosis, 8 (2.7\%) showed subchondral cysts, 25 (8.3\%) showed condylar hypoplasia or hyperplasia, and $3(1 \%)$ showed condylar bifidity.
Table 2. Comparison of osseous changes with regard to the right and left TMJs

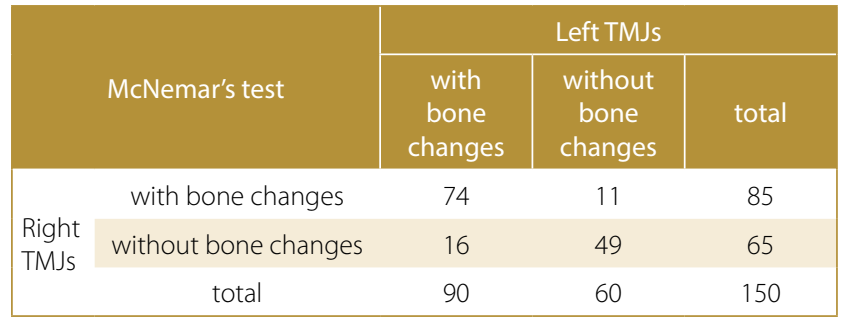

Table 3. Frequency distribution of osseous changes according to patients and TMJs

\begin{tabular}{|c|c|c|c|c|}
\hline Osseous changes & $\begin{array}{c}\text { Number } \\
\text { of patients } \\
(n)^{*}\end{array}$ & \begin{tabular}{|} 
Percentage \\
of patients \\
{$[\%]$}
\end{tabular} & $\begin{array}{c}\text { Number } \\
\text { of TMJs } \\
(n)^{* *}\end{array}$ & \begin{tabular}{|} 
Percentage \\
of TMJs \\
{$[\%]$}
\end{tabular} \\
\hline Condylar flattening & 71 & 47.3 & 108 & 36.0 \\
\hline Condylar erosion & 30 & 20.0 & 39 & 13.0 \\
\hline Condylar osteophytes & 26 & 17.3 & 30 & 10.0 \\
\hline Condylar sclerosis & 24 & 16.0 & 28 & 9.3 \\
\hline Subchondral cyst & 7 & 4.7 & 8 & 2.7 \\
\hline $\begin{array}{l}\text { Condylar hypoplasia/ } \\
\text { hyperplasia }\end{array}$ & 18 & 12.0 & 25 & 8.3 \\
\hline Bifid condyle & 3 & 2.0 & 3 & 1.0 \\
\hline $\begin{array}{l}\text { Flattening of the } \\
\text { articular eminence }\end{array}$ & 14 & 9.3 & 16 & 5.3 \\
\hline $\begin{array}{l}\text { Sclerosis of the } \\
\text { articular fossa }\end{array}$ & 3 & 2.0 & 3 & 1.0 \\
\hline $\begin{array}{l}\text { Erosion in the articular } \\
\text { fossa }\end{array}$ & 13 & 8.7 & 17 & 5.7 \\
\hline Joint space narrowing & 25 & 16.7 & 35 & 11.7 \\
\hline Loose bodies & 6 & 4.0 & 7 & 2.3 \\
\hline
\end{tabular}

${ }^{*}$ out of $\mathrm{N}=150 ;{ }^{* *}$ out of $\mathrm{N}=300$.
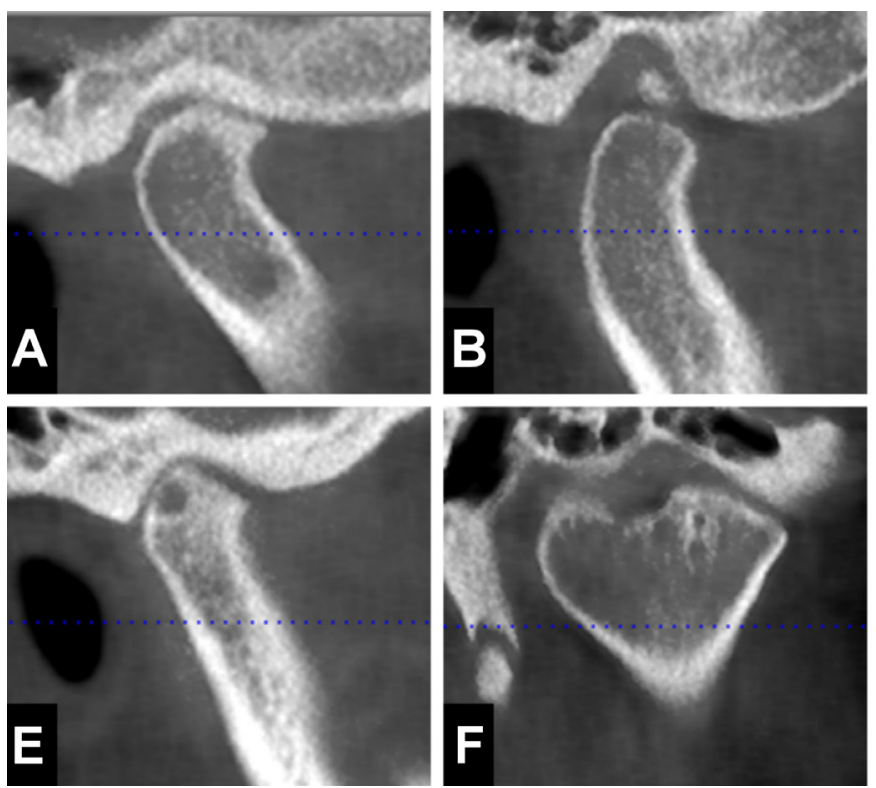
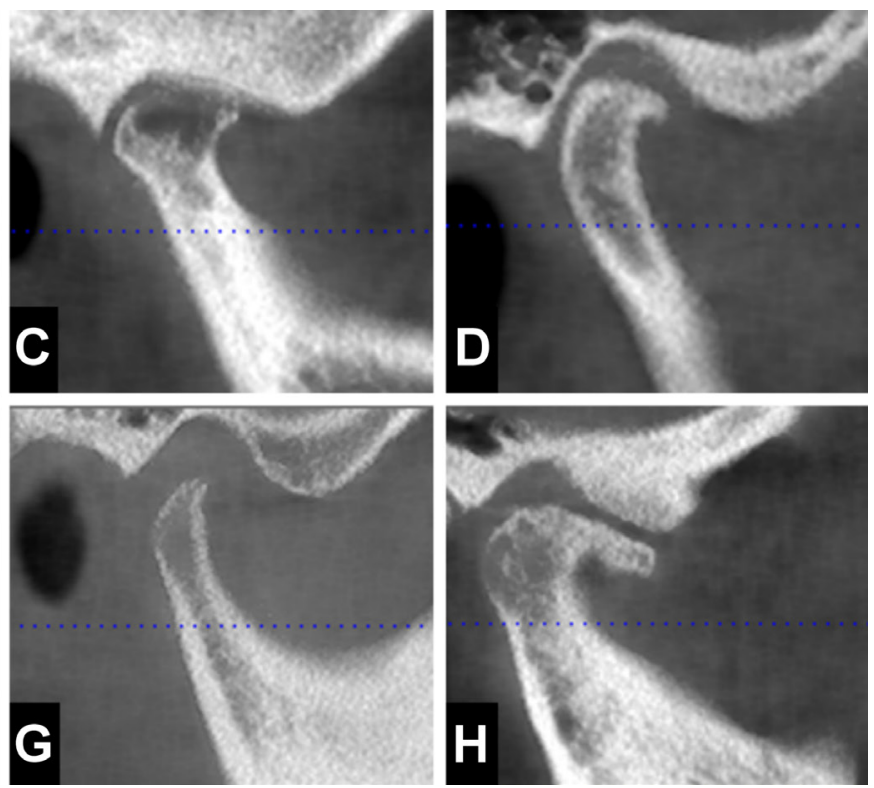

Fig. 1. Examples of the CBCT images of osseous changes in the temporomandibular joints (TMJS)

A - condylar flattening, subcortical sclerosis and joint space narrowing in a female aged 53 years; $B$ - loose calcified body in a male aged 62 years; $C$ - erosion in the condylar head and the sclerosis of the articular fossa in a female aged 58 years; D - osteophyte formation of the condyle in a female aged 45 years; $\mathrm{E}$ - subchondral cyst and the flattening of articular surfaces in a female aged 50 years; $F$ - bifid condyle in a male aged 48 years; $G$ - condylar hypoplasia in a female aged 20 years; $\mathrm{H}$ - osteophyte formation of the condyle, the sclerosis of the articular fossa and the flattening of the articular eminence in a male aged 69 years. 
The flattening of the articular eminence was observed in 16 (5.3\%) TMJs. Three (1\%) joints showed the sclerosis of the articular fossa and 17 (5.7\%) showed erosion in the articular fossa. Joint space narrowing was observed in $35(11.7 \%)$ TMJs and loose bodies were observed in $7(2.3 \%)$ joints.

Table 4 shows the frequency of osseous changes in the condyle and the respective mean ages. There were significant differences in the mean ages with regard to the absence and presence of condylar erosion $(p=0.001)$, osteophytes $(p=0.001)$ and loose bodies $(p=0.005)$. No differences were found with respect to condylar flattening, condylar sclerosis or subchondral cysts.

Table 5 shows the frequency of changes related to the articular fossa, the articular eminence and joint space, and the respective mean ages. Significant differences were found in the mean ages with regard to the absence and presence of erosion in the articular fossa $(p=0.006)$ and joint space narrowing $(p=0.017)$. No differences were found with respect to the flattening of the articular eminence or the sclerosis of the articular fossa.

Table 4. Frequency of osseous changes in the condyle and the respective mean ages

\begin{tabular}{|c|c|c|c|c|}
\hline Osseous changes & $\begin{array}{l}\text { Number } \\
\text { of TMJs } \\
\text { (n) }\end{array}$ & $\begin{array}{c}\text { Percentage } \\
\text { of TMJs } \\
{[\%]}\end{array}$ & $\begin{array}{c}\text { Age } \\
\text { [years] }\end{array}$ & $p$-value \\
\hline $\begin{array}{l}\text { Condylar flattening } \\
\text { present } \\
\text { absent }\end{array}$ & $\begin{array}{l}108 \\
192\end{array}$ & $\begin{array}{l}36.0 \\
64.0\end{array}$ & $\begin{array}{l}38.95 \pm 17.09 \\
36.27 \pm 18.21\end{array}$ & 0.212 \\
\hline $\begin{array}{l}\text { Condylar erosion } \\
\text { present } \\
\text { absent }\end{array}$ & $\begin{array}{r}39 \\
261\end{array}$ & $\begin{array}{l}13.0 \\
87.0\end{array}$ & $\begin{array}{l}45.87 \pm 18.81 \\
35.95 \pm 17.35\end{array}$ & 0.001 \\
\hline $\begin{array}{l}\text { Condylar osteophytes } \\
\text { present } \\
\text { absent }\end{array}$ & $\begin{array}{r}30 \\
270\end{array}$ & $\begin{array}{l}10.0 \\
90.0\end{array}$ & $\begin{array}{l}49.00 \pm 16.53 \\
35.93 \pm 17.51\end{array}$ & 0.001 \\
\hline $\begin{array}{l}\text { Condylar sclerosis } \\
\text { present } \\
\text { absent }\end{array}$ & $\begin{array}{r}28 \\
272\end{array}$ & $\begin{array}{r}9.3 \\
90.7\end{array}$ & $\begin{array}{l}41.28 \pm 18.70 \\
36.36 \pm 17.37\end{array}$ & 0.157 \\
\hline $\begin{array}{l}\text { Subchondral cyst } \\
\text { present } \\
\text { absent }\end{array}$ & $\begin{array}{r}8 \\
292\end{array}$ & $\begin{array}{r}2.7 \\
97.3\end{array}$ & $\begin{array}{l}45.00 \pm 7.40 \\
37.02 \pm 17.99\end{array}$ & 0.212 \\
\hline $\begin{array}{l}\text { Loose bodies } \\
\text { present } \\
\text { absent }\end{array}$ & $\begin{array}{r}7 \\
293\end{array}$ & $\begin{array}{r}2.3 \\
97.7\end{array}$ & $\begin{array}{l}55.57 \pm 20.63 \\
36.80 \pm 17.56\end{array}$ & 0.005 \\
\hline
\end{tabular}

Data concerning age presented as mean \pm standard deviation (SD).

\section{Discussion}

Cone-beam computed tomography imaging has been widely applied in the temporomandibular region, and has been proven to have superior diagnostic reliability in the detection of osseous abnormalities in TMJ as compared to plain radiography and conventional tomography. ${ }^{12,13}$ Conebeam computed tomography is found to be comparable to multi-slice CT in the detection of morphological changes in TMJ, and consequently is preferable to CT, as it comes with a lower radiation dose and high diagnostic reliability
Table 5. Frequency of changes in the articular eminence, articular fossa and joint space, and the respective mean ages

\begin{tabular}{|c|c|c|c|c|}
\hline Osseous changes & $\begin{array}{l}\text { Number } \\
\text { of TMJs } \\
\text { (n) }\end{array}$ & $\begin{array}{c}\text { Percentage } \\
\text { of TMJs } \\
{[\%]}\end{array}$ & $\begin{array}{c}\text { Age } \\
\text { [years] }\end{array}$ & $p$-value \\
\hline $\begin{array}{l}\text { Flattening of the } \\
\text { articular eminence } \\
\text { present } \\
\text { absent }\end{array}$ & $\begin{array}{r}16 \\
284\end{array}$ & $\begin{array}{r}5.3 \\
94.7\end{array}$ & $\begin{array}{l}45.31 \pm 17.46 \\
36.78 \pm 17.77\end{array}$ & 0.062 \\
\hline $\begin{array}{l}\text { Sclerosis of the } \\
\text { articular fossa } \\
\text { present } \\
\text { absent }\end{array}$ & $\begin{array}{r}3 \\
297\end{array}$ & $\begin{array}{r}1.0 \\
99.0\end{array}$ & $\begin{array}{l}45.33 \pm 10.59 \\
37.15 \pm 17.88\end{array}$ & 0.430 \\
\hline $\begin{array}{l}\text { Erosion in the } \\
\text { articular fossa } \\
\text { present } \\
\text { absent }\end{array}$ & $\begin{array}{r}17 \\
283\end{array}$ & $\begin{array}{r}5.7 \\
94.3\end{array}$ & $\begin{array}{l}49.38 \pm 15.88 \\
37.07 \pm 17.96\end{array}$ & 0.006 \\
\hline $\begin{array}{l}\text { Space narrowing } \\
\text { present } \\
\text { absent }\end{array}$ & $\begin{array}{r}35 \\
265\end{array}$ & $\begin{array}{l}11.7 \\
88.3\end{array}$ & $\begin{array}{l}43.97 \pm 16.12 \\
36.35 \pm 17.88\end{array}$ & 0.017 \\
\hline
\end{tabular}

Data concerning age presented as mean $\pm S D$.

in evaluating the bone structures of TMJ. However, CBCT does not display Hounsfield units (HU) as in medical CT, ${ }^{14}$ and is more sensitive to artefacts caused by motion and metal objects. ${ }^{5,6}$ Despite the superior features of CBCT imaging in the detection of bone alterations, diagnostic information is limited to osseous morphology, cortical bone integrity and subcortical osseous changes. Magnetic resonance imaging (MRI) is indicated when soft-tissue pathology or an inflammatory condition is suspected. ${ }^{4,7}$

Prior studies on CBCT evaluating the effect of the voxel size on the detection of osseous defects in TMJ have demonstrated that images reconstructed with a smaller voxel size $(\leq 0.2 \mathrm{~mm})$ have a higher spatial resolution and adequate diagnostic accuracy. ${ }^{15,16}$

The detection of degenerative changes in TMJ is substantial in both symptomatic and asymptomatic patients. Radiographic findings give important information regarding the presence and severity of bone alterations in TMJ. Since some of these alterations may be part of an agerelated remodeling process or may comprise a physiological response, they can occur in asymptomatic patients. Hence, it is not always possible to correlate the radiographic data with the clinical status. ${ }^{11,17}$ The CBCT scans included in this study were taken with the aim of imaging TMJs and were retrieved from the computer database. Consequently, the CBCT assessments did not take into account the patients' clinical status.

The present study was designed to evaluate the prevalence and imaging characteristics of bony changes in TMJ, and intended to identify the relationship between each bony change of OA and age. The radiographic evaluation of osseous changes was made based on the RDC/TMD image analysis criteria. ${ }^{2}$ Of the 150 patients who were referred for the evaluation of TMJs, 101 (26 males and 75 females) had the findings of TMJ OA. Some studies have reported that women are more likely to develop OA, which is mainly 
attributed to the hormonal differences between men and women., ${ }^{9,18}$ The potential role of sex hormones has been suggested in articular bone resorption and degeneration. ${ }^{20}$

The prevalence of osseous changes in TMJ detected in this study $(67.3 \%)$ was similar to the results reported by dos Anjos Pontual et al. (71\%) and Chang et al. (73\%), which may be due to the fact that all the patients included in the sample were referred for the CBCT examination with the initial diagnosis of a TMJ disease. ${ }^{18,21}$

The patients with changes of TMJ OA ranged in age from 10 to 82 years, with a mean age of 38.9 years, which was significantly higher as compared to those without any findings (mean age: 33.8 years; range: $10-90$ years; $p=0.02$ ). This result indicates that $\mathrm{OA}$ is common even in children and young adults, and is in agreement with the findings of other authors. ${ }^{18,22,23}$ Some researchers have reported an association between an increasing age and the prevalence of TMJ OA, ${ }^{9,18}$ whereas others have found no such correlation. ${ }^{24,25}$

In the present study, bony changes in the condyle were more frequently detected than changes in the articular eminence and articular fossa. The most frequent finding in this study was condylar flattening, which is mostly consistent with previous studies. ${ }^{9,18,19,24}$ However, this finding is incompatible with the results reported by Massilla Mani and Sivasubramanian, who found erosion as the predominant finding, ${ }^{26}$ and by Nah, who found sclerosis to be the most common finding. ${ }^{27}$ The discrepancy between these results may be attributed to gender and age differences, racial/ethnic disparity and the diagnostic criteria for OA.

The current findings, showing no significant mean age differences with regard to the absence and presence of condylar flattening, may suggest that this bony change might be a physiological response rather than a sign of age-related degeneration.

As degeneration progresses into the bony structures of TMJ, changes in bone surfaces occur, and the progress eventually results in bone erosion. The present results demonstrated that condylar erosion is more prevalent in older patients. ${ }^{10}$

In this study, the mean age of the patients with TMJ osteophytes was significantly higher as compared to the patients without osteophytes, which is in accordance with previous studies, reporting a higher prevalence of TMJ osteophytes at older age. ${ }^{9,28}$

At the advanced stage of TMJ OA, the structural deterioration of the subchondral bone leads to the thickening of the subchondral bone plate and an increase in bone density becomes evident. This elevated bone density is called subcortical sclerosis and has been strongly associated with the formation of subchondral cysts. ${ }^{29}$ No significant differences were found in the mean ages with regard to either the absence and presence of subcortical sclerosis or the absence and presence of subchondral cysts in this study.

Although loose joint bodies were amongst the less frequent condylar findings in this study, a significant difference was noted between the mean ages of the patients with and without loose bodies. Additionally, all cases with loose bodies were associated with other findings of condylar OA, such as erosion, sclerosis, osteophytes, and cyst formation. According to Ahmad et al., the presence of loose bodies may be considered as an indicator of OA in cases of the concomitant presence of other features of TMJ OA. ${ }^{2}$

The flattening of the articular eminence and erosion in the articular fossa were the most common temporal bone changes of OA in this study. The mean age of the patients with erosion in the articular fossa was significantly higher as compared to the patients with a normal articular fossa. However, no difference was found for the flattening of the articular eminence, although the $p$-value was close to being significant $(p=0.062)$.

The sclerosis of the articular fossa was the least common radiographic finding in this study (1\%). The present results are consistent with the studies in which the mean ages of the patients were similar with regard to the absence and presence of the sclerosis of the articular fossa. ${ }^{24,25}$

The RDC/TMD criteria suggest the evaluation of the joint space in a maximum intercuspation position of the condyle, because the joint space can change during mastication or mouth opening. ${ }^{2}$ The narrowing of the joint space was one of the common alterations in this study, which coexisted with other signs of OA in all cases. The current findings suggest that joint space narrowing in all directions may be a feature of $\mathrm{OA}$.

\section{Conclusions}

In conclusion, degenerative changes in TMJ may reflect an age-related bone remodeling process. Older patients may have more common findings of $\mathrm{OA}$, such as condylar and articular erosion, osteophytes, loose joint bodies, and joint space narrowing.

\section{ORCID iDs}

Nagihan Koç () https://orcid.org/0000-0002-3339-7783

\section{References}

1. Okeson JP. Management of Temporomandibular Disorders and Occlusion. $7^{\text {th }}$ ed. St. Louis, MO: Mosby; 2014:155.

2. Ahmad M, Hollender L, Anderson Q, et al. Research diagnostic criteria for temporomandibular disorders (RDC/TMD): Development of image analysis criteria and examiner reliability for image analysis. Oral Surg Oral Med Oral Pathol Oral Radiol Endod. 2009;107(6):844-860.

3. Schmitter M, Essig M, Seneadza V, Balke Z, Schröder J, Rammelsberg P. Prevalence of clinical and radiographic signs of osteoarthrosis of the temporomandibular joint in an older persons community. Dentomaxillofac Radiol. 2010;39(4):231-234.

4. Barghan S, Tetradis S, Mallya S. Application of cone beam computed tomography for assessment of the temporomandibular joints. Aust Dent J. 2012;57(Suppl 1):109-118.

5. Honda K, Larheim TA, Maruhashi K, Matsumoto K, Iwai K. Osseous abnormalities of the mandibular condyle: Diagnostic reliability of cone beam computed tomography compared with helical computed tomography based on an autopsy material. Dentomaxillofac Radiol. 2006;35(3):152-157. 
6. Larheim TA, Abrahamsson AK, Kristensen M, Arvidsson LZ. Temporomandibular joint diagnostics using CBCT. Dentomaxillofac Radiol. 2015;44(1):20140235.

7. Ferreira LA, Grossmann E, Januzzi E, de Paula MV, Carvalho AC. Diagnosis of temporomandibular joint disorders: Indication of imaging exams. Braz J Otorhinolaryngol. 2016;82(3):341-352.

8. Dworkin SF, LeResche L. Research diagnostic criteria for temporomandibular disorders: Review, criteria, examinations and specifications, critique. J Craniomandib Disord. 1992;6(4):301-355.

9. Alexiou K, Stamatakis H, Tsiklakis K. Evaluation of the severity of temporomandibular joint osteoarthritic changes related to age using cone beam computed tomography. Dentomaxillofac Radiol. 2009;38(3):141-147.

10. Gynther GW, Tronje G, Holmlund AB. Radiographic changes in the temporomandibular joint in patients with generalized osteoarthritis and rheumatoid arthritis. Oral Surg Oral Med Oral Pathol Oral Radiol Endod. 1996;81(5):613-618.

11. Kiliç SC, Kiliç N, Sümbüllü MA. Temporomandibular joint osteoarthritis: Cone beam computed tomography findings, clinical features, and correlations. Int J Oral Maxillofac Surg. 2015;44(10):1268-1274.

12. Hintze $\mathrm{H}$, Wiese $\mathrm{M}$, Wenzel $\mathrm{A}$. Cone beam $\mathrm{CT}$ and conventional tomography for the detection of morphological temporomandibular joint changes. Dentomaxillofac Radiol. 2007;36(4):192-197.

13. Honey OB, Scarfe WC, Hilgers MJ, et al. Accuracy of cone-beam computed tomography imaging of the temporomandibular joint: Comparisons with panoramic radiology and linear tomography. Am J Orthod Dentofacial Orthop. 2007;132(4):429-438.

14. Mah P, Reeves TE, McDavid WD. Deriving Hounsfield units using grey levels in cone beam computed tomography. Dentomaxillofac Radiol. 2010;39(6):323-335.

15. Patel A, Tee BC, Fields H, Jones E, Chaudhry J, Sun Z. Evaluation of cone-beam computed tomography in the diagnosis of simulated small osseous defects in the mandibular condyle. Am J Orthod Dentofacial Orthop. 2014;145(2):143-156.

16. Librizzi ZT, Tadinada AS, Valiyaparambil JV, Lurie AG, Mallya SM Cone-beam computed tomography to detect erosions of the temporomandibular joint: Effect of field of view and voxel size on diagnostic efficacy and effective dose. Am J Orthod Dentofacial Orthop. 2011;140(1):e25-e30.

17. Palconet G, Ludlow JB, Tyndall DA, Lim PF. Correlating cone beam CT results with temporomandibular joint pain of osteoarthritic origin. Dentomaxillofac Radiol. 2012;41(2):126-130.

18. dos Anjos Pontual ML, Freire JSL, Barbosa JMN, Frazão MAG dos Anjos Pontual A, Fonseca da Silveira MM. Evaluation of bone changes in the temporomandibular joint using cone beam CT. Dentomaxillofac Radiol. 2012;41(1):24-29.

19. Campos MI, Campos PS, Cangussu MC, Guimarães RC, Line SR. Analysis of magnetic resonance imaging characteristics and pain in temporomandibular joints with and without degenerative changes of the condyle. Int J Oral Maxillofac Surg. 2008;37(6):529-534.

20. Yasuoka T, Nakashima M, Okuda T, Tatematsu N. Effect of estrogen replacement on temporomandibular joint remodeling in ovariectomized rats. J Oral Maxillofac Surg. 2000;58(2):189-197.

21. Chang MS, Choi JH, Yang IH, An JS, Heo MS, Ahn SJ. Relationships between temporomandibular joint disk displacements and condylar volume. Oral Surg Oral Med Oral Pathol Oral Radiol. 2018;125(2):192-198.

22. Alkhader M, Ohbayashi N, Tetsumura A, et al. Diagnostic performance of magnetic resonance imaging for detecting osseous abnormalities of the temporomandibular joint and its correlation with cone beam computed tomography. Dentomaxillofac Radiol. 2010;39(5):270-276.

23. Zhao YP, Zhang ZY, Wu YT, Zhang WL, Ma XC. Investigation of the clinical and radiographic features of osteoarthrosis of the temporomandibular joints in adolescents and young adults. Oral Surg Oral Med Oral Pathol Oral Radiol Endod. 2011;111(2):e27-e34.

24. Walewski LÂ, Tolentino ES, Yamashita FC, Iwaki LCV, da Silva MC. Cone-beam computed tomography study of osteoarthritic alterations in the osseous components of temporomandibular joints in asymptomatic patients according to skeletal pattern, gender, and age. Oral Surg Oral Med Oral Pathol Oral Radiol. 2019;128(1):70-77.
25. Al-Ekrish AA, Al-Juhani HO, Alhaidari RI, Alfaleh WM. Comparative study of the prevalence of temporomandibular joint osteoarthritic changes in cone beam computed tomograms of patients with or without temporomandibular disorder. Oral Surg Oral Med Oral Pathol Oral Radiol. 2015;120(1):78-85.

26. Massilla Mani FM, Sivasubramanian SS. A study of temporomandibular joint osteoarthritis using computed tomographic imaging. Biomed J. 2016;39(3):201-206.

27. Nah KS. Condylar bony changes in patients with temporomandibular disorders: A CBCT study. Imaging Sci Dent. 2012;42(4):249-253.

28. Wiese M, Svensson P, Bakke M, et al. Association between temporomandibular joint symptoms, signs, and clinical diagnosis using the $\mathrm{RDC} / \mathrm{TMD}$ and radiographic findings in temporomandibular joint tomograms. J Orofac Pain. 2008;22(3):239-251.

29. Li G, Yin J, Gao J, et al. Subchondral bone in osteoarthritis: Insight into risk factors and microstructural changes. Arthritis Res Ther. 2013;15(6):223. 